\title{
O CONTRÔLE DE QUALIDADE NA INDÚSTRIA PAULISTA
}

O contrôle de qualidade não é mais um «luxo» administrativo: é, sim, uma necessidade imperiosa para a maior produtividade e lucratividade da emprêsa.

Até que ponto adotou nossa indústria os princípios e as técnicas mais recomendadas no terreno do contrôle de qualidade ? A fim de verificar qual a repercussão dos conceitos e dos métodos administrativos modernos no setor em foco, em nossas emprêsas, conduzimos uma pesquisa (1) junto a 35 indústrias paulistas, no ano de 1960. Apresentamos aqui os resultados essenciais obtidos naquele inquérito, com 0 fito, sobretudo, de comparar a teoria elaborada pelos especialistas no ramo com a prática seguida pelas firmas locais.

Após algumas palavras introdutórias sôbre o contrôle de qualidade e um breve relato do método seguido na pesquisa, examinaremos os problemas mais prementes de qualidade em nosso parque manufatureiro; compararemos, a seguir, as soluções dadas por nossas emprêsas com os preceitọs e métodos mais avançados no assunto e apresentaremos, finalmente, algumas sugestões sôbre o que talvez possa ser feito para melhorar a administração do contrôle de qualidade na indústria paulista.

CLAUDE MACHLINE - Professor-Adjunto da Escola de Administração de Emprêsas de São Paulo, Departamento de Administração da Produção.

(1) «O Contrôle de Qualìdade da Indústria Paulista», Claude Maehline, Monografia a ser publicada pela Fundação Getúlio Vargas. 
O que é Contrôle de Qualidade

O contrôle de qualidade reúne tôdas as atividades que visam a prevenção dos defeitos de fabricação e não se restringe sòmente à função de inspeção. Além da verificação das matérias-primas, do produto em fabricação e acabado, das ferramentas e dos calibradores, inclui a investigação das causas dos defeitos, a escolha dos métodos e dos planos de inspeção, a análise dos dados relativos às perdas e às reclamações, a determinação do nível de qualidade desejado no mercado, a recuperação do refugo e o estabelecimento das especificações de compra, além de outras funções necessárias à coordenação dos esforços produtivos, de modo que, no nível mais econômico, seja possível proporcionar ao freguês inteira satisfação.

E conveniente frisar que o contrôle de qualidade não detém as responsabilidades diretas pela percentagem do refugo, nem por um padrão insatisfatório de qualidade. Essas responsabilidades são da produção. Mas o contrôle de qualidade deve estar apto a inspecionar um número sempre maior de peças, sempre mais ràpidamente, com menor mão-de-obra, menos erros e menos atritos humanos.

\section{Amostra e Método Usados na Pesquisa}

Os estabelecimentos que participaram dêste inquérito foram escolhidos subjetivamente. Não tentamos obter uma amostra "ao acaso", por meio de algum processo probabilístico de seleção. Esforçamo-nos por incluir em nossa pesquisa as indústrias que, a nosso ver, poderiam possuir um programa bem elaborado de contrôle de qualidade. Assim, construímos nossa amostra com nomes de entidades prestigiosas, "líderes" nos seus ramos, cuja reputação deriva da excelência dos produtos, da dominação no mercado ou da pujança econômica. Procuramos as firmas significativas, não as representativas.

Escolhemos as companhias de modo a obter certa variedade de atividades fabris, concentrando-nos, entretanto, em setores nos quais a natureza do produto e o rigor das tolerân- 
cias justificariam um contrôle bem montado. Demos, assim, certa preponderância às indústrias mecânica e automobilística, em relação às outras classes de atividades manufatureiras.

Nossa amostra incluiu o seguinte número de emprêsas de cada ramo :

Transformação de minerais não metálicos

(Vidraria e Cerâmica) ................... 5

Metalurgia . ....................... 2

Mecânica . ......................... 11

Material Elétrico e de Comunicações ........... 3

Material de Transporte (Construção e Montagem).. 6

Mobiliário . . ....................... 1

Borracha . ........................ 1

Química e Farmacêutica ................. 3

Têxtil . ........................ 1

Serviços industriais de Utilidade Pública ........ 1

Transportes Aéreos . ................... 1

Total ......... 35

Quanto ao tamanho, eis como se subdividiam as companhias entrevistadas :

Mais de 1000 funcionários ................ 13

De 200 a 1000 funcionários ................. 14

Menos de 200 funcionários ................. 8

Total

Para conseguirmos as informações desejadas, entrevistamos pessoalmente funcionários que ocupavam cargos de chefia do contrôle de qualidade ou da inspeção, ou tinham posição de destaque no setor em aprêço. A fim de facilitar e uniformizar as entrevistas, valemo-nos de um questionário impresso. Muitas das perguntas que fizemos eram "não dirigidas", isto é, deixavam ao entrevistado ampla liberdade na formulação da resposta. 
Os Problemas de Qualidade das Nossas Indústrias

Examinemos primeiro alguns problemas de qualidade mencionados pelos dirigentes e técnicos com os quais conversamos. A lista que segue cobre, na ordem de importância, as dificuldades mais freqüentemente relatadas.

\section{A - Carência de Inspetores Qualificados}

Recrutar e manter o pessoal de inspeção qualificado constituem as maiores preocupações dos responsáveis pelo contrôle de qualidade nas indústrias mecânicas e, em geral, nos ramos de desenvolvimento recente em nosso país. No ramo automobilístico, por exemplo, não se encontrando às vêzes em um único indivíduo todos os talentos necessários ao desempenho de certas inspeções delicadas (como ajustagem da carroçaria), lança-se mão de duas pessoas para perfazê-las. Após o custoso treino na própria indústria, os inspetores especializados são fàcilmente perdidos para os concorrentes, que lhes acenam com ofertas tentadoras, seja em cargos produtivos, melhor remunerados, seja em postos de supervisão.

\section{B - Falta de Constância nas Matérias-Primas e nos Suprimentos}

A variabilidade na qualidade das matérias-primas e dos suprimentos, quer se trate de minérios, chapas metálicas, componentes ou embalagens, representa um percalço constante à obtenção de uma qualidade uniforme. Não é possivel confiar no fornecedor, qualquer que seja; perde-se muito tempo na inspeção das remessas de materiais comprados.

Um fabricante de lavadeiras automáticas declarou-nos que desmonta e examina cuidadosamente um certo número de relés, reostatos e motores de cada partida adquirida, ainda que as remessas anteriores da mesma fonte tenham sido tôdas satisfatórias. Não se trata de falta de confiança na idoneidade do fornecedor, mas suspeita de que o mesmo possa ter usado, inadvertidamente, na montagem do relé, constituintes de qualidade inferior, a êle supridos por um subfornecedor. 


\section{C - Falta de Apoio por Parte da Direção}

A maioria de nossas emprêsas cresceu muito ràpidamente. $O$ volume de produção, mais do que a qualidade e o volume do refugo, tem sido a preocupação principal dos dirigentes. $O$ departamento de contrôle de qualidade, criado, mais de uma vez, tardiamente, é considerado, pela linha de produção, um intruso, para não dizer um estôrvo. Os controladores não são. prestigiados, sua importância para a supressão do refugo e o aumento da produção não é reconhecida.

Uma fábrica de mobiliários já possuiu um departamento de contrôle de qualidade, porém extinguiu-o por medida de economia; considera, no momento, de tôda conveniência o seu restabelecimento, mormente pelo fato de que parte substancial de suas vendas se efetua agora à indústria automobilística, mais rigorosa em suas exigências do que os demais consumidores. Em muitas firmas, o departamento de contrôle de qualidade tem que lutar àrduamente para se ver instituído de tôdas as atribuições que constituem seu apanágio natural e provido de todos os meios necessários ao bom desempenho de sua missão.

\section{D - Falta Generalizada de Mentalidade de Qualidade}

Os encarregados do contrôle de qualidade, em nossas indústrias, ressentem-se da falta geral de "mentalidade" de qualidade, tanto por parte da direção da emprêsa, quanto dos homens de produção, dos fornecedores e, paradoxalmente, dos. próprios fregueses. "Mentalidade" de qualidade sòmente tem a direção que se organiza para um contrôle preventivo completo, que planeja e administra eficazmente um programa total de contrôle de qualidade.

A qualidade não é ainda um caso de "consciência profissional" para certo número de dirigentes, nem é concebível que o seja para os que fizeram súbita fortuna num mercado tão favorável ao fornecedor como o que prevaleceu longos anos entre nós; à medida que a concorrência aumenta, os indus- 
triais convencem-se da necessidade de estabelecer um contrôle parcial, mas sempre permanecem muitos pontos sem contrôle algum, pelos quais se processará uma evasão à qualidade.

Típica desta ideologia é a atitude de certo fabricante de material sanitário (2). Em determinada época, suas banheiras e pias, depois de instaladas nas residências, rachavam espontâneamente. $O$ industrial contratou tardiamente um consultor. Porém, como o defeito desapareceu tão ràpidamente como surgira, êle deixou de se preocupar com a ocorrência, conquanto fôsse de fundamental importância para sobrevivência de sua emprêsa.

Nas indústrias pequenas, o chefe de fabricação é quase sempre o maior entendido em assuntos de qualidade e sua prática em usar o tato, a vista, o olfato, no exame do produto, é respeitada e invejada por todos os subordinados. Supervisores dêste tipo têm inevitável desconfiança de complicados e custosos aparelhos de inspeção e tendem a desprestigiar os inspetores que os usam.

Outro exemplo da falta de interêsse pela qualidade é fornecido por uma firma de produtos cosméticos que elabora considerável variedade de produtos; a mesma dispõe de três químicos para supervisionar a fabricação das remessas dos produtos, mas não é feito nenhum contrôle sistemático das propriedades dos mesmos; nenhuma inspeção de qualquer espécie é efetuada, tampouco, sôbre as unidades embaladas; cada seis meses, conforme consta dos contratos, uma amostra é enviada para análise aos laboratórios das firmas estrangeiras que detêm as marcas ou as patentes dos seus produtos. Essa emprêsa originou-se há um quarto de século, no fundo de um quintal. Hoje é uma potência no ramo de produtos de toucador !

Os subterfúgios usados pelos fornecedores para fazer "passar" lotes de peças defeituosas foram denunciados por elevado nú-

(2) Esta indústria não pertence à nossa amostra. 
mero de entrevistados. Atrasam-se as remessas, obrigando o freguês a escolher entre parar sua linha de fabricação ou aceitar algum refugo; entregam-se remessas pequenas, pois estas têm maior probabilidade de ser aceitas, para uma mesma proporção de peças defeituosas, do que partidas grandes.

Muitos fregueses industriais foram também acusados de não possuir "mentalidade" de qualidade. Tem ocorrido a miúdo a devolução de remessas inteiras, devido à presença de uma única peça defeituosa, na amostra que o inspetor de recepção extraiu do lote recebido. Ouvimos a queixa de que as peças são, às vêzes, rejeitadas por defeitos "insignificantes" ou "inevitáveis", que "passariam" no estrangeiro. Os compradores foram culpados de recusar remessas por mero capricho, sempre que mudam suas diretrizes de inspeção ou de compras, de submeter desenhos com tolerâncias "impossíveis" e, finalmente, de esquecer, às vêzes, dados essenciais nas especificações.

\section{Observância dos Princípios de Contrôle de Qualidade}

Tentaremos agora verificar se determinadas normas de organização encontraram boa acolhida em nossas indústrias. Não existem dogmas em assuntos de administração; todos os preceitos devem ser adaptados às condições particulares vigentes na emprêsa. A observação de que nossas indústrias infringem certas normas teòricamente recomendadas não deve, portanto, ser interpretada como uma crítica.

\section{A - Princípio de Definição de Cargos}

Uma descrição pormenorizada das funçōes e das atividades de cada indivíduo poderá ser feita vantajosamente, a fim de evitar atritos e evasão a responsabilidades. As atribuições dos elementos de cúpula serão especificadas num "manual de cargos" ou "livro de funções".

Apenas cinco emprêsas, dentre as companhias visitadas, possuíam um caderno de funções, o que evidencia a existência de um alto grau de "informalismo" em nossas organizações. 
Nas emprêsas pequenas, pode-se justificar a ausência de definições funcionais, mas, nas firmas de porte, uma "Carta Magna", conhecida e aceita por todos, evitará as "guerrilhas" ent́re "camarilhas" e eliminará a "terra de ninguém" administrativa.

\section{B - Princípio de Definição de Linhas de Comando}

As relações de autoridade e subordinação entre os membros da organização devem ser claramente definidas.

As posições hierárquicas e as linhas de comando direto e "funcional" deverão ser esquematizadas num organograma, mesmo que êste não seja capaz de exprimir tôda a complexidade do jôgo entre as funções, nem o cunho particular que cada personalidade imprime à sua posição oficial.

Tôda emprêsa, òbviamente, apresenta certa organização e poderia, portanto, possuir um organograma; às vêzes, êste não existe no papel, por ser considerado desnecessário, em vista da extrema simplicidade da organização; ou acha-se inconveniente exibi-lo, talvez pelo receio de criar melindres.

Das 35 emprêsas visitadas, 28 possuíam um organograma formal, afixado em lugar visível ou traçado sem hesitação pelo informante. Porém, em apenas 22 emprêsas, o organograma era do conhecimento geral, frequientemente revisto pelos $\mathrm{di}$. rigentes e considerado de grande importância para a determinação da hierarquia. Em outras seis, o organograma existia apenas no fundo de uma gaveta e não era tido como uma representação fiel da organização. Das sete emprêsas restantes, cinco não consideravam um organograma necessário e duas pretendiam criar o seu brevemente; essas cinco emprêsas contavam tôdas com menos de 200 funcionários.

Parece-nos que a conveniência de se ter um organograma, pelo menos como instrumento de estudo da organização, já foi compreendida pela maioria de nossos industriais. Poucos dirigentes sentem-se à vontade quando têm de revelar que 
sua emprêsa não possui um organograma. A existência de um gráfico organizacional não significa que não haja problemas estruturais de tôda a espécie, na firma em aprêço; pode ser uma condição necessária, porém, nunca suficiente para se obter uma boa organização. Mas a inexistência de um organograma poderá sugerir que a firma se descuidou dos problemas de organização.

\section{C - Princípio da Adoção de Contrôle de Qualidade}

A função de contrôle de qualidade deve existir em tôda emprêsa. O produto será controlado em tôdas as fases de sua fabricação.

Poucas indústrias, dentre as que foram objeto de nossa pesquisa, desconhecem totalmente êsse lema; mas poucas também são as que o praticam integralmente. Dos três aspectos fundamentais da inspeção - inspeção de recebimento de materiais, inspeção de saída dos produtos e inspeção dos produtos em processo de fabricação - as duas primeiras fases são cumpridas por quase todos os nossos informantes, mas a terceira, a inspeção do processo, está sendo negligenciada, ou é feita de maneira obsoleta, por aproximadamente metade das firmas. Um punhado de estabelecimentos, apenas, estruturou um sistema integrado de contrôle de qualidade.

\section{D - Princípio da Departamentalização do Contrôle de Qualidade}

Deve existir, em tôda emprêsa de certo porte, um departamento dedicado ao contrôle de qualidade, constituído de pessoas que se consagrem exclusivamente à fiscalização da qualidade.

Vinte e oito emprêsas, dentre as 35 que formavam nossa amostra, seguiram êsse ditado, criando um departamento, serviço ou setor de contrôle de qualidade ou de ins- 
peção. Nas demais sete firmas, tôdas as diversas inspeções são executadas por indivíduos isolados, sempre subordinados à produção, ou por responsáveis pela produção.

Entretanto, somente 14 dessas 28 sociedades que acabamos de mencionar delegam ao departamento de contrôle de qualidade todas as funçoes que constituem seu campo natural de ação. Nas outras 14, muitas atividades de contrôle de qualidade são desempenhadas por pessoas de produção.

\section{E - Principio de Autonomia do Contrôle de Qualidade}

O departamento de contrôle de qualidade precisa gozar de razoável independéncia $\mathrm{cm}$ relação à produção. A voz da qualidade não pode ser abafada pelos imperativos do faturamento. Para que as considerações relativas à quantidade não sobrepujem as concernentes à qualidade, convém que a inspeção se situe em um nivel hierárquico em que suas recomendações se façam ouvir. A arquitetura mais propícia ao equilíbrio de posição entre contrôle de qualidade e produção será, talvez, a que está esquematizada na Figura 1, em que o contrôle de qualidade responde diretamente à presidência.

\section{Figura 1: Controle de Qualidade Subordinado Diretamente à Presidencia.}

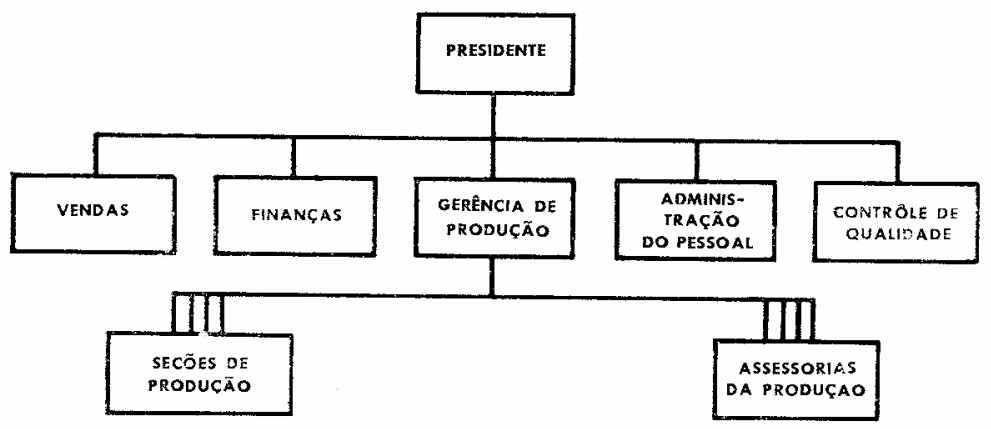

A edificação seguinte, em que o contrôle de qualidade é subordinado à gerència da fábrica, também é condizente com a autonomia do contròle de qualidade: (vide Figura 2). 
Figura 2: Contrôle de Qualidade Subordinado à Gerência Industrial.

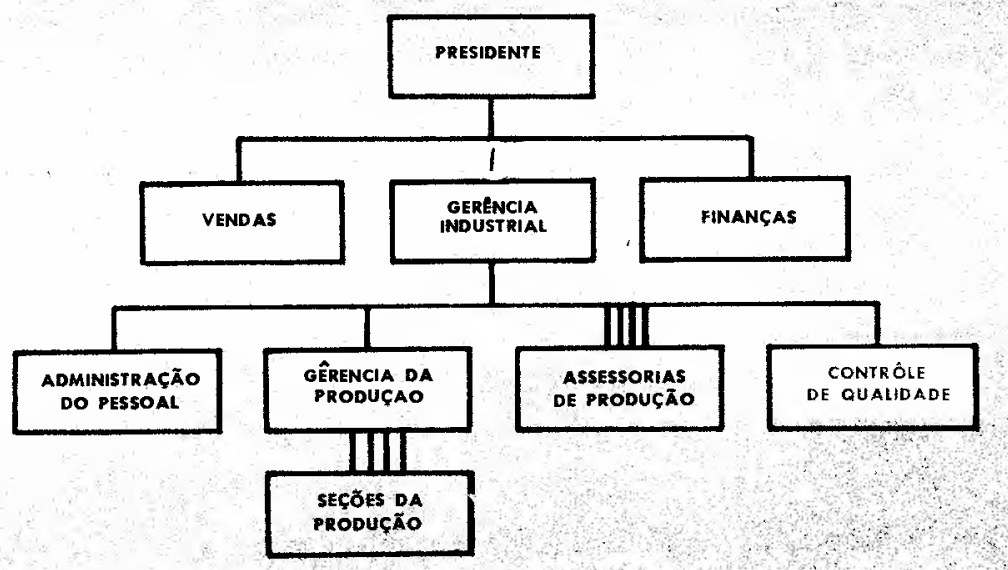

A existência dos dois arranjos estruturais esquematizados acima foi notada em 8 emprêsas, ao passo que a constituição representada no Gráfico 3, que segue, prevalccia em 18 organizações :

Figura 3: Contróle de Qualidade Subordinado a Geréncia da Produção.

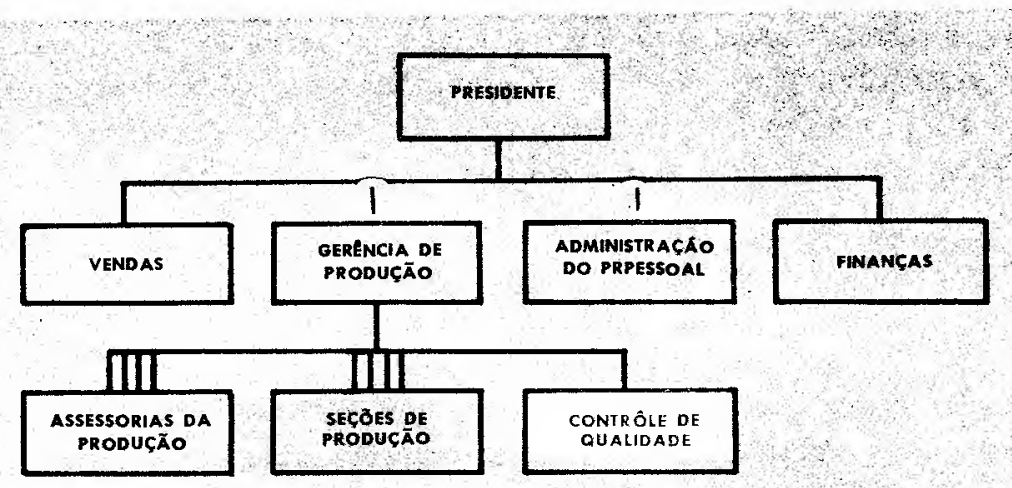

Pudemos observar que os dois primeiros arranjos são os preferidos pelas emprêsas de grande porte, ao passo que as firmas médias e pequenas adotam principalmente o último por scr mais condizente, talvez, com seus recursos humanos. 
Com esta última disposição, em que o contrôle de qualidade está subordinado diretamente à produção, a autonomia advogada no princípio em aprêço sòmente poderá manifestar-se quando a personalidade do chefe do contrôle não fôr subserviente e quando o chefe de produção possuir, ao menos em certo grau, "mentalidade" de qualidade.

$O$ contrôle de qualidade não deve ser executado por parte interessada. Em outras palavras, não convém que o comprador seja o inspetor dos suprimentos que êle mesmo adquire, nem que o operador seja $o$ juiz das peças que êle próprio fabrica. O contrôle feito por uma pessoa parcial é suspeito e, a rigor, deixa de ser contrôle.

Este ponto de vista foi geralmente admitido pelos dirigentes entrevistados, porém o oposto foi sustentado por outros:

"Com a inspeção do produto final a seu cargo, a produção estará em melhores condições para saber o que está fazendo", observou o gerente de uma fábrica de aparelhos eletro-domésticos, defendendo a organização vigente na sua emprêsa.

Quando a firma fôr pequena, não se justificando, portanto, a contratação de inspetores especializados, quando que os operadores forem pagos por hora, ou lhes fôr descontada a produção de peças defeituosas, quando a operação fôr muito automatizada e quando, finalmente, a inspeção fôr de técnica simples e não acarretar interrupção na produção, os axiomas de separação e autonomia do contrôle de qualidade perdem sua fôrça, podendo-se admitir que sua inobservância não signifique, necessàriamente, a violação do seu espírito.

Mencionemos, por exemplo, o caso de uma fábrica de motores Diesel, instalada, aliás, há pouco tempo, entre nós. $\mathrm{O}$ operador, nessa indústria, é o seu próprio inspetor: a diretriz da firma é a de contratar operadores caros, com especialização e prática muito superiores àquelas exigidas pela operação que executam. Será desnecessário acrescentar que os operários são pagos por hora. A emprêsa, porém, pretende instituir um sistema de incentivos; o freio a uma produção descontrolada será a obrigação, sempre que fôr constatado um defeito, de o operador responsável consertar a peça por conta própria. 
F-Princípio de Assessoria do Contrôle de Qualidade

A responsabilidade suprema pela obtenção da qualidade desejada é da produção. O contrôle de qualidade é uma função de assessoria, sem responsabilidade direta pela qualidade do produto.

Tôdas as pessoas entrevistadas, qualquer que seja sua posição nas firmas, revelaram possuir o ponto de vista ortodoxo acêrca dessa questão; há um consenso geral de que a produção "faz" a qualidade e de que o contrôle de qualidade deve criar os planos e providenciar os meios para a produção "fazer" a qualidade. A inspeção deve "acompanhar" a produção, sempre ajudando-a, nunca interferindo negativamente, seja por um arranjo físico que impeça o fluxo natural dos produtos, seja impondo "papeladas" que dupliquem inùtilmente as da produção, seja ainda obstando às boas relações entre os homens de produção e contrôle.

A única responsabilidade direta outorgada à inspeção, em grande número das emprêsas visitadas, é a de não deixar "passar" peças defeituosas, quer seja na recepção dos suprimentos, na transferência do produto de uma seção à seção subsequiente, quer na escolha final. Nas palavras de um técnico com o qual palestramos: "o inspetor deve ser inflexível; sòmente êle deve dizer se a peça é boa ou ruim. Aquilo que deve ser rejeitado não pode ser tolerado sob nenhuma consideração; o inspetor tem a obrigação de ser desconfiado e inflexível".

o princípio de assessoria implica em que o contrôle de qualidade deve desfrutar de prestígio, a fim de que seus planos, métodos e recomendações sejam acatados pela linha de produção. Nesse ponto, existem profundas divergências entre as pessoas que entrevistamos: na maioria das emprêsas, a contribuição pedida ao departamento de contrôle de qualidade é passiva, não indo além da atividade de inspeção; numa pequena minoria, a participação do contrôle de qualidade é ativa, sendo recebidas de bom grado as suas sugestões quanto às causas e às curas dos defeitos; encontramos tôda a gama de matizes entre êsses dois extremos. 


\section{Adoção das Técnicas Atualizadas de Contrôle de Qualidade}

Indaguemos agora da extensão em que se viram aprovadas pela nossa indústria algumas técnicas específicas de contrôle de qualidade propostas por especialistas alienígenas ou aqui mesmo desenvolvidas. Agruparemos os métodos examinados em três categorias:

A - Processos destinados a promover o levantamento de dados relativos à qualidade.

B - Técnicas de desenvolvimento da consciência de qualidade entre os funcionários da emprêsa.

C - Métodos estatísticos de inspeção e de contrôle preventivo da qualidade.

\section{A - Levantamento de Dados Relativos à Qualidade}

a) Classificação de Defeitos

A elaboração de uma lista de todos os defeitos que possam ocorrer no produto representa um valioso investimento para a descoberta de fontes de perturbações na fabricação e constitui um passo preliminar para sua erradicação.

Um "atlas" de defeitos circulará entre os responsáveis e alertá-los-á sôbre as causas das imperfeições e os possíveis remédios. Servirá como valiosíssimo repositório da tradição, na luta contra os males que afetam a qualidade do produto. Cientificamo-nos de que sòmente uma emprêsa (cerâmica) valeu-se dêsse meio.

Coleções de amostras, evidenciando os vários defeitos, serão, também, de grande valia ao inspetor-chefe, para conservar um padrão constante de escolha. Uma única emprêsa (vidraria) utiliza êsse recurso em tôda sua plenitude.

Nem todos os defeitos têm a mesma importância. A classificação das falhas em três categorias, conforme 
a sua gravidade, e a atribuição de um valor numérico de demérito a cada classe facultarão o cálculo de um "índice de qualidade", permitindo comparar periòdicamente o padrão e o nível de qualidade alcançados; o mesmo servirá de base a um eventual concurso de qualịdade entre linhas de fabricação ou entre fábricas; proporcionará, ainda, o estabelecimento de um paralelo com os produtos análogos da concorrência, ou com um nôvo produto que se pretende lançar no mercado.

Apesar de sua considerável utilidade, a classificação ponderada dos defeitos sòmente é praticada por quatro das emprêsas visitadas.

b) Avaliação de Fornecedores

Não se admite que uma firma progressista assuma uma atitude passiva em relação aos fornecedores : procurar novos mananciais de abastecimento, que prometem melhores condições quanto ao preço, à qualidade ou ao prazo de entrega, é um imperativo, máxime em nosso meio, onde tamanhos óbices se antepõem à obtenção de um fluxo regular de chegada dos materiais.

Algumas emprêsas - temos em mente em particular duas companhias montadoras de veículos - têm seguido uma política agressiva de compras, colocando seus laboratórios, suas oficinas e seus engenheiros à disposição dos fornecedores, destarte incitando-os a que se lancem à fabricação de novos produtos e à : puração de sua qualidade. Essas organizações marıtêm em dia um fichário de todos os fornecedores ativos e potenciais, saudável atitude que não encontrou a receptividade que merecia (3). Sabemos, também,

(3) Já concluído êste inquérito, soubemos que certa emprêsa do ramo automobilístico viu-se a braços com uma crise de peças, que determinou a paralização parcial de suas atividades, precisamente por ter negligenciado o arrolamento de novos abastecedores. Criou ulteriormente seu serviço de assistência aos fornecedores, o qual conta hoje com 8 engenheiros. As outras emprêsas automobilísticas estão seguindo êsse exemplo. 
que pelo menos três firmas de aparelhos eletro-domésticos e algumas companhias que instalam equipamento elétrico pesado permutam entre si informações atinentes à qualidade oferecida pelos fornecedores existentes na praça.

c) Registro das Reclamações

Pudemos observar que o levantamento sistemático de dados relativos a reclamações e chamadas de serviço ainda é negligenciado em nossas indústrias. Poucas são as firmas que realizam êsses estudos e a maioria das que assim procedem o fazem há pouco tempo. A inércia posta pelos departamentos de serviços e de vendas à colheita e ao fornecimento das estatísticas tem sido um grande obstáculo encontrado pelos departamentos de contrôle de qualidade na regularização de um serviço dessa espécie.

As firmas que conservam amostras e fatos relativos a cada ordem de fabricação completada, que registram nas peças, por meio de um código apropriado, os dados essenciais à elucidação de qualquer reclamação eventual, que catalogam as queixas por territórios, revendedores e períodos e que computam o número de chamadas de serviço por milhar de unidades vendidas, bem como o "custo da garantia" por unidade, constituem uma restrita minoria.

\section{B - Desenvolvimento da Consciência de Qualidade}

Os meios enumerados a seguir começam a ser divulgados entre nós para desenvolver a consciência de qualidade entre os servidores da emprêsa :

a) Colocação, nos locais de trabalho, de cartazes acentuando a importância da qualidade. - Apenas em duas fábricas percebemos a existência de letreiros dêsse gênero.

b) Exibição, em cada seção, de gráficos mostrando a tendência do refugo nos últimos períodos; de tabelas indicando a produção diária de peças boas e defeituo- 
sas; de um quadro evidenciando o "índice de qualidade" atingido diàriamente por cada linha de fabricação. - Seis fábricas têm adotado um ou outro dêsses métodos.

c) Exposição das peças defeituosas, em local de passagem obrigatória por parte dos operários. - Uma metalúrgica procede dessa maneira (4).

d) Criação de uma caixa de sugestões, onde são admitidas idéias que concernem à qualidade. - Nove dentre as emprêsas estudadas possuem uma caixa de sugestões, mas apenas quatro incentivam a colheita de contribuições relativas à qualidade.

e) Publicação, no "jornalzinho", de tópicos relativos à qualidade e aos controladores. - Das emprêsas que percorremos, 17 publicam um jornal com certa regularidade, mas até então tinha agradado a bem poucos a possibilidade de fazer campanha de qualidade por êsse meio.

f) Publicações de cartas e noticiários relacionados com qualidade. - Nenhuma emprêsa vale-se dêste recurso, mas algumas colocam observações impressas nos formulários de contrôle de produção que circulam entre o pessoal da fábrica.

g) Conferências periódicas de qualidade, que podem ser efetuadas em nível de gerência ou de chefia. Pràticamente tôdas as emprêsas realizam reuniões esporádicas e mais da metade organiza reuniões regulares de qualidade. Apenas duas promovem reuniões entre chefes e operários.

h) Emissão de relatórios de qualidade. - Algumas firmas, dentre as visitadas, fazem circular, nos departamentos interessados, um relatório diário ou semanal discriminando a percentagem de peças de cada tipo, refugadas em cada seção (5).

(4) Soubemo: que, após nossa visita, uma emprêsa (cerâmica) resolveu também exibir diàriamente as peças defeituosas.

(5) Uma das emprêsas adotou recentemente êsse sistema, verificando-se uma queda imediata e apreciável do refugo. 
i) Concursos de qualidade. - Um lanifício - nãc incluído na amostra - promove um concurso de qualidade entre as escolhedoras de lã. Três emprêsas (eletrônica, vidro) patrocinam um concurso de qualidade entre as diversas seções. Duas fábricas (eletrônica, vidro) participam de um concurso internacional permanente dessa natureza.

j) Produção de uma fita versando sôbre qualidade. Ao tempo de nossa pesquisa, nenhuma indústria tinha produzido um filme dedicado ao assunto de qualidade. Apraz-nos assinalar que, desde então, uma companhia automobilística realizou uma película de dez minutos de tempo de projeção, focalizando seus laboratórios e seus aparelhos de contrôle de qualidade.

\section{C - Utilização dos Métodos Estatísticos}

Já faz três décadas que as técnicas da estatística são aplicadas, em outros países, ao contrôle de qualidade dos produtos manufaturados. Examinaremos sucintamente o grau em que nossas indústrias aceitaram essas inovações.

a) No exame de muitas características do material, a inspeção de uma amostra, conduzida de acôrdo com um plano estatístico perfeitamente estabelecido, substitui vantajosamente a inspeção total ou a inspeção de uma percentagem da partida, por ser mais rápida, mais barata e permitir calcular os riscos de se cometer um êrro. Na inspeção de recebimento, quatro firmas de nossa amostra recorreram a planos estatísticos. Na inspeção do produto em processo ou acabado, cinco são as emprêsas que assim procedem.

b) Os gráficos de contrôle estatístico (também chamados gráficos de Shewhart, ou cartões de contrôle), são usados para seguir, durante a fabricação, as variações das características do produto. Esses gráficos estatísticos são usados extensivamente em apenas três das emprêsas visitadas e, num grau menor, em mais seis fábricas. 
Vemos que são poucas as emprêsas que usam métodos estatísticos. Reina certa desconfiança em relação à sua aplicação em nosso meio, justificada, verdade seja dita, pelo nível de qualidade inconstante e pouco satisfatório de muitas linhas de fabricação. As técnicas estatísticas permitem-nos aplicar três importantes princípios de contrôle de qualidade:

1) - substituir, na medida do possível, verificações "post mortem" por contrôle corretivo durante o processo;

2) - substituir, sempre que possível, verificações do tipo qualitativo "bom ou ruim", "passa ou não passa", por contrôle quantitativo, que dê informes numéricos;

3) - substituir, sempre que possível, verificações totais por inspeções parciais.

Cabe-nos, entretanto, observar que o uso dessas técnicas modernas não permitirá ao contrôle de qualidade fugir à sua maior responsabilidade, que é a de estabelecer um sistema de informações por meio do qual se saiba, tão ràpidamente quanto possível, da ocorrência de novos defeitos ou de excessiva percentagem de defeitos. Assim, o sistema de vigilância do contrôle de qualidade deve estar equipado para comunicar imediatamente à produção as anomalias que requerem providências.

\section{Conclusões}

Não nos atrevendo, embora, a extrapolar a todo nosso parque industrial as observações feitas em número tão reduzido de emprêsas, forçoso é concluir que, no assunto em debate, como em tudo o mais, somos um país de contrastes. Contrastes entre as emprêsas, pois, se a maior parte de nossas fábricas ainda está "engatinhando" nas áreas de planejamento, organização e contrôle, uma honrosa minoria edificou um programa muito satisfatório de contrôle de qualidade. Contrastes internos, também, pois é frequiente ver-se justapostos, debaixo do mesmo teto fabril, o melhor e o pior em matéria de homens e de equipamentos. 
Fôsse-nos solicitado enunciar algumas recomendações de natureza geral para o aprimoramento do contrôle de qualidade em nossas indústrias, indicaríamos os seguintes pontos como os mais dignos de reter a atenção dos responsáveis por êsse setor :

\section{1. ${ }^{\circ}$ - Diretriz de Qualidade}

A direção da emprêsa deve convencer-se da importância sempre crescente da qualidade do produto, bem como da necessidade de respeitar o público consumidor. É provável que a única orientação compatível com a sobrevivência da emprêsa consista em adotar uma diretriz positiva de qualidade. Passou a era de "apostar" na produção a baixo preço e vil qualidade. E findou, sobretudo, a época dos enganos ao público e dos "estelionatos" de qualidade.

\section{$2^{\circ}$ ) - Organização da Emprêsa}

O primeiro passo na adoção dos métodos administrativos atualizados consiste em certificar-se de que as funções básicas de boa administração, isto é, o planejamento, a organização, a direção, o provimento de pessoal e o contrôle são desempenhadas. A omissão de uma qualquer dessas atividades pode ser fatal. Deve-se atentar ao preenchimento de tôdas as funções do contrôle de qualidade; a demarcação das responsabilidades e autoridades, o delineamento de encargos, a definição exata das relações entre linha e assessoria precisam ser feitas.

\section{$3^{\circ} .^{\circ}$ - Apoio ao Departamento de Contrôle de Qualidade}

As funções de assessoria devem ser convenientemente prestigiadas e remuneradas, na organização. O culto pelo feitor, pelo "homem" que manda e paga, precisa ser complementado pelo respeito ao cérebro que calcula e controla. Confiram-se ao departamento de contrôle de qualidade as funções que lhe competem, atribua-se-lhe uma posição adequada dentro da organização e, principalmente, dê-se-lhe o apoio necessário ao cabal desempenho de sua missão. 


\section{4. $\left.{ }^{\circ}\right)$ - Uso dos Métodos Estatísticos}

A maior vantagem de se valer dos métodos estatísticos de contrôle de qualidade talvez resida na economia da preciosa mão-de-obra de inspeção. A desconfiança em relação à estatística, ao seu espírito e às suas possibilidades deve ser posta de lado; a absoluta necessidade de controlar preventivamente, ràpidamente e com segurança - com estatística - não pode mais ser negligenciada.

\section{5..$^{\circ}$ - Treinamento de Especialistas}

Quantas emprêsas assinam revistas, constituem bibliotecas? Quantas mandam seus especialistas a congressos, seus técni$\cos$ a cursos de aperfeiçoamento? Quantas operam escolinhas para seus auxiliares?

É certo que, das 35 emprêsas que visitamos, 29 possuem alguma ligação com uma companhia estrangeira, indo desde a afiliação estreita até o mero intercâmbio de informações técnicas. Mas a qualidade não pode ser simplesmente comprada ou copiada. A vista das inúmeras perplexidades que estrangulam nossas fábricas, somos levados a pensar que a assistência estrangeira, conquanto imensamente útil, é bem menos eficaz do que se poderia imaginar. A disseminação das soluções administrativas organizacionais e técnicas comprovadas em outras entidades locais encontra maior receptividade do que as importadas.

Os sete flagelos lendários que assolam a nacionalidade'desde tempos imemoriais — fome, pobreza, doença, ignorância, isolamento, improvisação e corrupção - acometem tôdas as nossas emprêsas. Para dêles nos livrarmos de um só golpe, o único recurso é educar o homem. É, sobretudo, no treinamento do operário, no aprimoramento do técnico e no desenvolvimento do dirigente que reside a solução das momentosas vicissitudes, de qualidade e outras, com que nos havemos . 